\title{
A measured approach
}

\section{Alex Colville's exhaustive search for mathematical probity.}

\section{Martin Kemp}

There is often a point in research of a mathematical nature when the solution to a problem is sensed before it is proved. An anticipatory instinct tells us when something feels right. For someone publishing a scientific paper, the proof is of course essential. For an artist who works towards pictorial solutions, the proof of the pudding is in the viewing, and the instinctual element of 'rightness' remains paramount.

Alex Colville, to my mind the best Canadian artist of his time, works with a slow-burning meditative persistence on the geometrical structures that underlie his pictures. The concept for the picture is triggered by his vision of a pregnant moment in the life of things. The picture shape that 'fits' the subject is then altered by repeated geometrical structuring using complex overlays from Colville's repertoire of inscribed circles, squares, triangles, logarithmic spirals and ratios. Human proportionality, which is based on the system of head lengths beloved of Renaissance architects and more recently Le Corbusier, has an important role in those paintings that involve his cast of wordless characters.

Series of carefully dated studies are made, looking like the storyboard for a film, but destined never to extend in time beyond one enigmatic still. Concentrated flurries of intense design are interspersed with contemplative intervals. Motifs are rearranged and manoeuvred in space, as Colville seeks, for both the mathematical structures and the subject, the right organization of space, the right surface conjunctions and the right intervals. These are neither wholly calculated nor freely instinctual, but a combination of both.

The process behind the picture shown here, The Surveyor, is fairly typical, involving almost 30 drawings over 14 months during 19992000. The surveyor's transit with its splayed tripod is measured for precise transcription. A complex fretwork of lines drawn with straight-edge and compasses is intricately interwoven with the subjects, playing off those constituent parts that are most overtly geometrical with those whose order has been hidden behind the chaos of processes. Scales of head lengths are mapped on the compositional studies. Intricate sets of alternative diagonals structure the complex foreground region anchored by the legs of the tripod and surveyor. Tones and colours are positioned to see what works. All the while, neat calculations of scale keep everything in proportion.

The scene is in Nova Scotia, overlooking the tidal planes near Wolfville, where Colville lives. He is a local painter in the sense that Constable was local, creating art that has to draw nourishment from scenes known intimately in order to find a wider truth. The surveyor, in this case a woman, stands on a ribbon of isolated road, absorbed in the act of measuring. But measuring what? She seems to have turned the precise eye of her instrument on the elusive curves of the tidal waterway, which are always in the process of coming and going.

Colville's art is underpinned by his quest for order from apparent disorder. He searches, like Piero della Francesca in the Renaissance or Georges Seurat in the late nineteenth century, for what we can find beneath and within the surface of appearances if we probe intensively enough. The visual reconstruction of order is hard won and fragile, like the order of society itself. For Colville, the quest, when conducted at the highest level, is a lonely one, drawing on deep resources, yet it is one we recognize and share.

The frame of Piero della Francesca's painting Flagellation (see Nature 390, 128; 1997), in which three mute figures stand in the foreground, closely grouped and emotionally dislocated from the main subject, once bore the inscription, "convenerunt in unum", which roughly means "they conspire together". Colville's art is one of wordless conspiracies in which he enrols us compellingly in his quiet narratives of the apparently ordinary. Below the surface are the strangeness and wonder, disorder and order, that have fired the quests of artists and scientists since the beginning of both art and science.

Martin Kemp is professor of the history of art at the University of Oxford, Oxford OX1 1PT, UK, and co-director of Wallace Kemp Artakt.

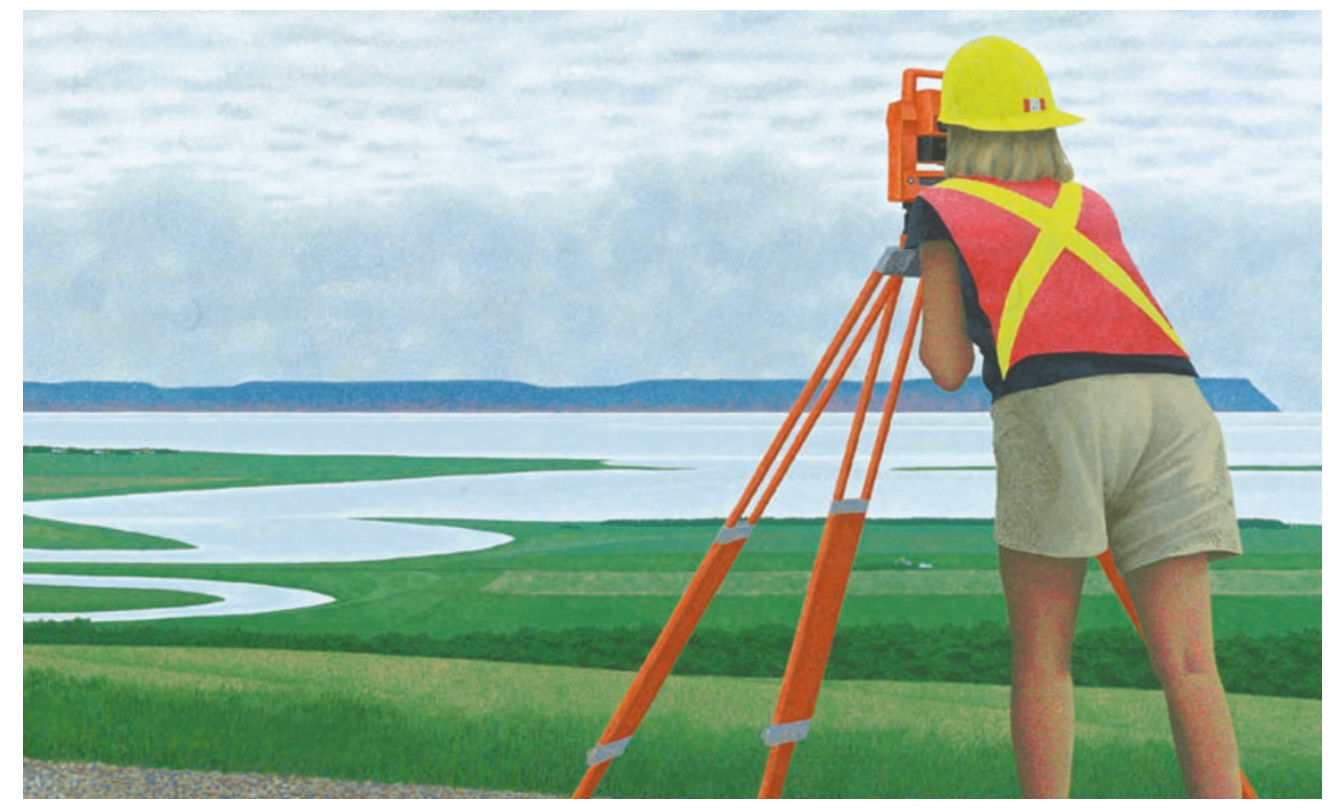

and operating clothes — long pre-dated Lister's spraying of open wounds with carbolic acid, which anyway turned out to be a cul-de-sac rather than the main highway of antiseptic surgery. John Waller has argued forcefully in his own book, Fabulous Science (Oxford University Press, 2002), that Lister was a tireless self-publicist, taking personal credit for a movement he did not start and to which he contributed relatively little.

So, are Dormandy's heroes giants stand- ing on each other's shoulders, or dwarfs treading on each other's toes? Are their stories myth or history? In reality, there is no clear demarcation: it is all down to points of view and motives. After all, one of the functions of myths is to answer questions about origins. Where did medicine come from? Who invented antiseptic surgery? But that is also one of the functions of history. Consider the subtitle of this book, Four Creators of Modern Medicine. However painstakingly collected and scrupulously verified, the real significance of historical 'facts' depends on the quality of the point of view for which they are marshalled. Of course, a point of view may be worth entertaining even if you do not actually accept it on the evidence, and that may depend on how it is put across. In this book, Dormandy puts his across rather well.

John Galloway is at the Eastman Dental Hospital, 256 Gray's Inn Road, London WC1X 8LD, UK. 